\title{
Efficacy of a Classroom Integrated Intervention of Phonological Awareness and Word Recognition in "Double-Deficit Children" Learning a Regular Orthography
}

\author{
Andreas Mayer ${ }^{1} \&$ Hans-Joachim Motsch ${ }^{1}$ \\ 1 Department of Rehabilitation and Special Education, Speech and Language Rehabilitation, University of \\ Cologne, Germany
}

Correspondence: Andreas Mayer, Department of Rehabilitation and Special Education, Speech and Language Rehabilitation, University of Cologne, Klosterstrasse 79b, D-50931 Cologne, Germany. Tel: 49-(0)22-1470-5507. E-mail: amayer2@uni-koeln.de

Received: June 24, 2014

Accepted: July 14, $2015 \quad$ Online Published: August 11, 2015

doi:10.5539/jel.v4n3p88

URL: http://dx.doi.org/10.5539/jel.v4n3p88

\begin{abstract}
This study analysed the effects of a classroom intervention focusing on phonological awareness and/or automatized word recognition in children with a deficit in the domains of phonological awareness and rapid automatized naming ("double deficit"). According to the double-deficit hypothesis (Wolf \& Bowers, 1999), these children belong to the group who show the most pronounced difficulties when learning how to read and write.

Our results suggest that children with a double deficit are at great risk of developing dyslexia unless they receive specific support. Moreover, the results of the intervention study are the first to show how German speaking children with a double deficit can be adequately supported within the framework of standard beginners' reading and writing lessons in inclusive classrooms so that impending difficulties in the acquisition of written language can be successfully prevented. The support measures focus on a training of phonological awareness and automatized processing of sublexical orthographic units. However, potential modifications of the training are currently being discussed since not all children in the training groups were able to benefit satisfactorily.
\end{abstract}

Keywords: dyslexia, phonological awareness, rapid automatized naming (naming speed), double deficit, classroom intervention

\section{Introduction}

Reading and spelling disabilities (dyslexia) are prevalent in children with language impairments (Catts et al., 2002). Combined with a deficit in reading comprehension, dyslexia often results in general learning difficulties. This is the reason why the majority of affected children and adolescents in Germany attended special schools where learning processes and language acquisition were specifically supported. Since the ratification of the UN convention on the rights of persons with disabilities in 2009, concomitant with the introduction of an inclusive school system, teachers in regular schools are increasingly confronted with having to offer adequate support for dyslexic children-not simply in explicit extra lessons, but within the regular lessons for the entire class.

The aim of this study is to evaluate the efficacy of intervention measures for double-deficit children which can easily be integrated into regular lessons.

Specific reading and spelling disabilities (dyslexia) belong to the most common school-related learning disorders in children and adolescents. Approximately 6-8\% of an age group suffer from difficulties when learning how to read and write (Shaywitz, Shaywitz, Fletcher, \& Escobar, 1990).

According to Lyon, Shaywitz, and Shaywitz (2003) and Tunmer and Greaney (2010), dyslexia is defined as a learning disorder which is characterized by deficits in phonological recoding and/or automatized word recognition as well as impaired orthographic skills. It can result from deficits in phonological processing as a consequence of abnormal neurobiological development and often goes hand in hand with language impairment. Dyslexia occurs irrespective of cognitive abilities and the provision of effective classroom instruction. It can 
have a negative influence on reading comprehension, as well as on the cognitive, linguistic and socio-emotional development.

"Skilled word recognition is seen as extremely important, perhaps essential, for the higher-level or more advanced aspects of reading, especially reading comprehension" (Kirby, Georgiou, Martinussen, \& Parilla, 2010, p. 342). Preventive efforts should thus concentrate specifically on this problem. This approach is also implemented in the support measures presented in this study.

Currently, researchers agree that the three linguistic-cognitive functions of phonological awareness, phonological working memory and rapid automatized naming (Wagner \& Torgesen, 1987) are closely related to reading and writing abilities.

Dyslexic children are, for example, often characterized by deficits in the area of phonological short-term memory ("phonological loop") and working memory, and significant correlations of these deficits and the children's performance in reading and writing are commonly found (Swanson, Zheng, \& Jerman, 2009). Nevertheless, the contribution of the working memory seems to be of especially low impact when both, phonological awareness and working memory, are considered simultaneously as predictors of reading and writing (Schatschneider \& Torgesen, 2004). This is the reason why this paper focuses on phonological awareness and rapid automatized naming (RAN).

Phonological awareness refers to the implicit and explicit ability to identify, synthesize, analyze and manipulate sublexical units (syllables, onset and rime, phonemes) of spoken language.

Rapid automatized naming (RAN) is defined as the ability to name familiar symbols (digits, letters, objects or colours) presented repeatedly in random order, in left-to-right serial fashion as quickly as possible (Wolf \& Bowers, 1999; Kirby et al., 2010; Norton \& Wolf, 2012). The key dependent variable is the total time needed to name the items. RAN tests were originally developed by Denckla and Rudel (1976) to identify a naming-speed deficit in children with reading impairments.

Currently, researchers generally agree that dyslexic children as a group are characterized by significantly poorer performance in both, phonological awareness and rapid naming, when compared to average readers (Denckla \& Rudel, 1976; Wolf, Bally, \& Morris, 1986; Meyer, Wood, Hart, \& Felton, 1998; Wimmer, 1993).

\section{The "Double-Deficit Hypothesis"}

The double-deficit hypothesis (Wolf \& Bowers, 1999; Wolf, O’Rourke, Gidney, Lovett, Cirino, \& Morris, 2000) complements the phonological-core-deficit hypothesis (Stanovic, 1988), which sees phonological awareness, RAN, the phonological memory and the categorical perception of certain phonemes as the main phonological areas that cause dyslexia.

The "double-deficit hypothesis" however interprets the RAN deficit as a core factor in developmental dyslexia, which is largely independent of phonological abilities. The theoretical reason for this postulated independence of the two functions is that not only the phonological component, but also visual, cognitive, linguistic and articulatory competences are involved in the complex construct of rapid naming. Empirical, analyses of the correlation of phonological awareness and RAN support this hypothesis. The analyses confirm that the two abilities are only moderately correlated with an overall correlation of approximately $r=.38$ (Swanson, Trainin, Necoechea, \& Hammill, 2003; Norton \& Wolf, 2012). Similar results were found by Wolf et al. (2002), Verhagen, Aarnoutse, and van Leeuwe (2008) and Mayer (2008). Additionally, regression analyses consistently report that RAN and phonological awareness account for unique variance in reading ability (Blachman, 1984; Bowers \& Swanson, 1991; Cornwall, 1992; Wagner, Torgesen, Laughon, Simmons, \& Rashotte, 1993; Manis, Doi, \& Bhadha, 2000).

Due to the largely independent but additive influences of phonological awareness and RAN skills on the acquisition of reading and writing (Lovett, Steinbach, \& Fritjers, 2000; Kirby, Pfeiffer, \& Parilla, 2003), the double-deficit hypothesis posits that children with a double deficit should be ranked among the group of children with the most severe difficulties in the acquisition of written language.

Kirby et al. (2003) were able to confirm this assumption. They measured phonological awareness and RAN in 161 children in senior kindergarten. Until grade 5, double-deficit children had the most pronounced problems and lagged behind the no-deficit participants by almost two years of achievement. Additionally, these children showed no sign of progression and it was unlikely that they would catch up at a later point in time.

Cronin (2013) and Torppa, Parrila, Niemi, Lerkkanen, Poikkeus, and Nurmi (2013) were able to confirm Kirby's et al. (2003) findings. The performance of the double-deficit group in phonological recoding, word recognition 
and reading comprehension lagged approximately one year behind their single-deficit peers and about three years behind the no-deficit group.

With regard to prevalence, the results of both, Torppa et al. (2013) and Mayer (2014), show that about $9 \%$ of each age group are affected by a double deficit.

\section{Significance of the Predictors in Pegular Orthographies}

The German orthography belongs to the alphabetic orthographies with a fairly regular grapheme-phoneme correspondence ("forward regularity") and a much more ambiguous phoneme-grapheme correspondence ("backward regularity") (Wimmer \& Mayringer, 2002; Klicpera et al., 2013). Letters and letter combinations (e.g., $<$ ack $>,<$ ah $>,<$ ie $>$ ) in German are mostly pronounced the same (except for vowels and phonetic subtleties) The attribution of a phoneme or a phoneme combination to a respective letter (combination), however, is much less obvious. A long and tense [a:] for example can be written as $<$ a $>$ (e.g., $<$ Schal $>$, [scarf]), $<$ ah $>$ (e.g. $<$ Wahl $>$, [election]) or $<$ aa $>$ (e.g., $<$ Saal $>$, [hall]). For that reason, developing adequate reading accuracy is hardly a problem for German speaking children (Aro \& Wimmer, 2003). Learning the correct orthography, however, is a much longer learning process that most normally developing children haven't fully mastered at the end of primary school. Dyslexic children often still have difficulties with the orthography as adolescents or even in adulthood. With respect to reading abilities, a deficit in reading fluency with negative impacts on reading comprehension belongs to the core deficits of dyslexic children in German speaking countries.

When it comes to the significance of possible predictors in relatively transparent orthographies, the results of some studies suggest that the influence of phonological awareness is limited to reading skills within the first years of school. When looking at respective deficits in the long run, they mostly seem to affect the acquisition of a correct orthography (Moll, Fussenegger, Willburger, \& Landerl, 2009; Wimmer \& Mayringer, 2002; Berendes, Schnitzler, Willmes, \& Huber, 2010).

The general assumption is that phonological awareness functions as a predictor for inconspicuous performance in early reading and writing. However, not all children who show a deficit in phonological awareness during the pre-school years actually develop difficulties when learning how to read and write (Holopainen, Ahonen, \& Lyytinen, 2001; Landerl, Linortner, \& Wimmer, 1992). A likely reason is that the combination of phonics instruction with the systematic relationship between graphemes and phonemes in languages with a consistent orthography bolsters the performance of dyslexic students in the field of phonological awareness to such an extent that they do not necessarily experience reading and writing problems (Wimmer, Landerl, Linortner, \& Hummer, 1991).

Naming speed is supposed to be most closely related to automatized word recognition. Since a deficit in word recognition seems to be the major symptom of dyslexic children in languages with a transparent orthography, RAN has for almost ten years now been considered a particularly important and consistent predictor for reading and writing skills (Georgiou, Parilla, \& Liao, 2008; Brizzolara et al., 2006; van den Bos, Zijlstra, \& Spelberg, 2002; Wimmer, 1993; Papadopoulos, Georgiou, \& Kendeou, 2009; Escribano, 2007).

The negative effects of a RAN deficit become decidedly evident when children who develop normally begin to successfully supplement phonological recoding with the strategy of direct automatized word recognition. They have specific difficulties linking larger sub-lexical or lexical units to their phonemic equivalents; hence, they have to sound out every phoneme of a word and cannot move from the initial stage of slow laborious phonological recoding to the stage of fluent and rapid reading (Levy, 2001). Problems in reading comprehension are often seen as a result of a deficit in automatized word recognition.

\section{Intervention Options}

A training in phonological awareness and/or automatized processing of sublexical or lexical orthographic units are two of the most frequently discussed support measures for dyslexic children. In summary, a training in phonological awareness is particularly effective whenever the "phonological linkage hypothesis" (Hatcher, Hulme, \& Ellis, 1994) is taken into account-i.e., whenever a training of phonological awareness is combined with a training of sub-skills that are specifically related to the written language and when the training concentrates on the phoneme level (Bradley \& Bryant, 1983; Hatcher et al., 1994; Roth, 1999; Hatz \& Sachse, 2010).

However, studies from countries with shallow orthographies also indicate that an isolated training in phonological awareness should not be overestimated in its practical effects. Lundberg, Frost and Petersen (1988) were indeed able to prove the impact of phonological awareness in pre-school training situations on the 
acquisition of written language, but from a practical perspective this ultimately turned out to be irrelevant, since the IG only performed marginally better than the the CG (Schneider, Kuespert, Roth, \& Marx, 1997).

In summary, Torgesen, Wagner and Rashotte (1997) come to the conclusion that even the most effective phonologically oriented training programmes may lead to a better performance in phonological recoding but not to considerable improvement in direct word recognition and reading comprehension: "[ $\ldots]$ we have not yet demonstrated that we understand the conditions that need to be in place for children with phonologically based reading disabilities to acquire the level or type of phonetic reading skills that can be utilized within a self-teaching framework to produce advantages in the development of a rich orthographic reading vocabulary" (230).

Considering measures that aim at a deficit in RAN, training in naming speed has so far neither led to immediate improvements nor to positive effects on reading abilities (Berglez, 2002; de Jong \& Vrielink, 2004; Conrad \& Levy, 2011). Altogether, naming speed can be seen as an ability that changes over time due to maturation processes, but cannot be improved by additional training. It may yet be possible that longer instruction is more effective (Kirby et al., 2010).

If it is not possible to improve naming speed, devoting instructional time to orthographic processing and efficient word reading fluency may be a better idea. Methods focusing on holistic simultaneous processing skills of larger sublexical orthographic units could be suitable for "slow namers" because children with a naming-speed deficit have difficulties to become sensitive to orthographic units that frequently co-occur in print. This is due to slow identification of individual letters in a word and the impaired activation of single letters in a word in sufficiently close temporal proximity (Bowers, Golden, Kennedy, \& Young, 1994).

Levy, Bourassa, and Horn (1999) point out that children with a naming-speed deficit are put at a disadvantage by methods that focus on the word level. Yet, they may profit from intervention programmes that present smaller, segmented orthographic units in high frequency. Levy (2001) summarizes her research results pointing out that interventions in which words that share the same sublexical units (for example the same rime) are presented together may be particularly effective in children with a RAN deficit as their attention is drawn to consistent spelling patterns.

In this context, the results of Thaler, Ebner, Wimmer and Landerl (2004) as well as Hinitikaa, Landerl, Aro, and Lyythinen (2008) showed that it is possible to increase the reading speed by a repeated confrontation with frequently occurring sublexical units. Nevertheless, the positive effects are strongly limited to the trained word material and transfer to general reading abilities is conspicuously rare.

Studies published so far all focus on interventions for children with reading deficits but not specifically on children with a double deficit. As far as we know, the study at hand is the first to evaluate the efficacy of training measures in children with a double deficit.

A thorough analysis of the existing research data and literature about the double deficit hypothesis led us to elicit the questions used to plan and implement the study at hand. Studies from countries with regular orthographies collectively come to the conclusion that phonological awareness is not necessarily a risk factor for developing dyslexia. Hence, this study was to answer the question whether German-speaking children with a double deficit also belong to the group of children with the most severe difficulties when learning how to read and write. With regard to the training, we focused on the question whether classroom integrated methods that form the basis for a successful acquisition of written language by training phonological awareness can be successfully complemented by measures focusing on the holistic processing of sublexical units and hence on the automatization of the reading process. The aim is to investigate whether a combination of these two training aspects can minimize the risk of double-deficit children of developing dyslexia.

Hypotheses:

-Double-deficit children perform significantly poorer in tests that measure reading and writing skills than no-deficit and single-deficit children (phonological-awareness-deficit children, naming-speed-deficit children) if they do not receive specific training within the first two years of school.

-Reading and writing difficulties in double-deficit children can be reduced by a classroom-integrated intervention programme that trains phonological awareness as well as automatized word recognition.

\section{Method}

The results of the study at hand are part of an extensive longitudinal study which was conducted between 2011 and 2013 in Mettmann (North-Rhine Westphalia, Germany), a district near Cologne that predominantly consists 
of medium-size cities (20,000 to 60,000 inhabitants) (Mayer, 2014). Children just starting school from 23 different schools $(n=1002)$ were tested for phonological awareness and RAN at the beginning of the school year 2011/12 (T1). The children were assigned to one of four groups according to the double-deficit hypothesis.

All children who performed at least within average (i.e., T-score $>40$ ) in both phonological awareness and RAN in the "Test of Phonological Awareness and Naming Speed" (TEPHOBE, Mayer 2013, chapter 5.3) were classified as part of the "no deficit group" ( $\mathrm{n}=684,68.4 \%)$. Children with average performance in terms of RAN (T-score $>40$ ) and a deficit in phonological awareness (T-score $<40$ ) formed the "phonological-awareness-deficit group" (pad, $\mathrm{n}=125,12.5 \%)$. The "naming-speed-deficit group" ( $\mathrm{nsd}, \mathrm{n}=108$, $10.8 \%$ ) consisted of those children that had average scores in phonological awareness (T-score $>40$ ) but performed below average with regard to RAN (T-score $<40$ ). The double-deficit group that the paper at hand focuses on ( $\mathrm{dd}, \mathrm{n}=85,8.5 \%)$ was composed of those children who performed at least one standard deviation below the mean $(\mathrm{T}$-score $<40)$ in both functions.

The aim of the study was to test if it is possible to support children with a double deficit in inclusive settings with the help of feasible training programmes which can be conducted by the regular teacher with the whole class. So it is quite unique that the intervention measures were not conducted in extra lessons by external staff but instead by the regular teacher with the whole class and within the regular reading lessons in grade one. That is why a completely randomized distribution of the children, based on individual performance, was not possible. If an intervention is conducted within one institution there is always the risk of communication or mutual interference of the subjects beyond the framework of the test conditions. Because teachers hardly ever have the opportunity to implement exhaustive individual intervention conditions, a cluster randomization based on classes was chosen over an individual randomization for the study at hand (Chenot, 2009; Kerry \& Bland, 1998).

In order to measure the efficacy of the training, reading fluency (Wuerzburger Leise Leseprobe, WLLP-R [Wuerzburger Silent Reading Test-Revised], Schneider, Blanke, Faust, \& Kuespert, 2011), reading comprehension (ELFE 1-6, Lenhard \& Schneider, 2006) and spelling skills (Deutscher Rechtschreibtest fuer die erste und zweite Klasse, DERET 1-2+ [German Spelling Test for First and Second Grade], Stock \& Schneider 2008) of all participating children were gauged at the end of grade one and two (T3, T4).

\subsection{Participants}

A total of 1002 children who started elementary school in September 2011 were included in the study. In German-speaking countries, children do not receive reading instruction in kindergarten, so most of the first graders neither know the letters of the alphabet nor have they already mastered the alphabetic principle of the German orthography.

In this paper, the focus is on the double-deficit group. This group consisted of 85 children (aged: 6; 4, SD: 0; 4; $52.6 \%$ male); they were assigned to four different intervention conditions in a school-based but randomized order $(\mathrm{IG}=$ Intervention group, $\mathrm{CG}=$ Control group).

- IG 1: Training of phonological awareness during the first half of grade one $(n=28)$

- IG 2: Training of phonological awareness during the first half, and training of word recognition on a sublexical level during the second half of grade one $(\mathrm{n}=25)$

- IG 3: Training of word recognition on a sublexical level during the second half of grade one $(n=15)$

- CG: Implementation of the approach preferred by the teacher ("business as usual") $(n=17)$

The control group cannot be seen as a traditional control group since these children also received their regular reading and writing lessons by their classroom teacher in the same intensity as the training groups. According to the teachers of the control group, training in phonological awareness played a substantially and temporally similar role to that in the training groups.

At the end of grade one, the reading and writing skills of 78 children were available (IG 1: $\mathrm{n}=25$, IG 2: $\mathrm{n}=25$, IG $3: \mathrm{n}=11$, CG: $\mathrm{n}=17)$. At the end of grade two, the reading and writing skills of 61 double-deficit children could be tested ((IG 1: $n=24$, IG 2: $n=20$, IG 3: $n=9$, CG: $n=8$ ). The comparatively high drop-out rate between grade one and two can be explained by the grave difficulties of some double-deficit children of the CG in their reading and writing acquisition. These children were then either sent to special needs schools or had to repeat the first grade. 


\subsection{Test Procedure}

There were two pre-intervention test sessions, the first one (T1) in September 2011 and the second one (T2) one week later. During T1, phonological awareness and naming speed of the first graders of all participating schools were tested. The tests were conducted by special needs teachers.

During T2, all double-deficit children were additionally tested concerning their nonverbal cognitive abilities, language comprehension, grammatical development and short-term memory. These tests were conducted and evaluated by university students for special needs education and speech and language pathology.

After these first two test sessions, the training of phonological awareness in the IG 1 and IG 2 started. It comprised 14 weeks and was thus finished in January 2012. The training of word recognition (Mayer 2012) began immediately afterwards in IG 2 and IG 3, and continued for ten weeks. Both training programmes comprised two lessons per week and were implemented by the regular teacher with the entire class during the officially assigned early reader lessons.

At the end of grade one and two (T3, T4), reading fluency, reading comprehension and spelling skills were gauged. These tests were conducted by special needs teachers.

All teachers involved in the study had been explicitly prepared for conducting and assessing the tests and training programmes by the author of the intervention programmes. The entire corpus of material, including detailed instruction and schedules for the training lessons, was provided.

\subsection{Measures}

\section{Phonological awareness and RAN}

To assess phonological awareness and RAN, the standardised "Test of Phonological Awareness and Naming Speed" (TEPHOBE, Mayer, 2013) was used.

TEPHOBE contains four tasks that test phonological awareness at the beginning of grade one. In the first task (synthesis of onset and rime), the instructor presents a word segmented into onset und rime; the child has to choose the matching picture (which best represents the word) out of four pictures. In the second task (phoneme synthesis), the instructor presents a word divided into single phonemes. Again, the child has to choose the correct picture (which best represents the word) from a selection of four pictures. The third task (rhyming) requires the child to choose those two pictures out of four which stand for words that rhyme. In the last task (phoneme categorization), the child has to choose two pictures from a total of four. This time, the pictures are to represent words that start with the same phoneme. Each task consists of seven items. Each correct response scores one point, resulting in a maximum score of 28 . This score was subsequently converted into a T-score with a mean of 50 and a standard deviation of 10 points.

The reliability for the individual tasks and the entire test of phonological awareness had a Cronbach's alpha beetween .71-.78.

The RAN Test in TEPHOBE consists of the conventional RAN tests with the categories letters, numbers, colours and objects based on Denckla and Rudel (1976). Since German-speaking children who are just starting school are hardly ever sufficiently acquainted with letters, naming speed was tested via RAN colours and RAN numbers. Both matrices consist of five different items (rot [red], gelb [yellow], gruen [green], blau [blue], braun [brown] or $2,4,5,6,8)$ which are repeated ten times each, so that the child has to name 50 items per task, in a serial left to right fashion.

The time needed for naming all items can be transferred into T-scores with a mean of 50 and a standard deviation of 10 points on the basis of the standardization sample. The reliability for the RAN Tests had a Cronbach's alpha between .78-.86.

Language measures

The receptive and productive language skills were measured using the "Entwicklungstest Sprache fuer Kinder zwischen vier und acht Jahren" ([Test of Language Development for Children between 4 and 8 years], Angermaier, 2007). The subtest "Language Comprehension" is a German version of the Sentence Structure Task of the CELF test (Wiig et al., 2003). It focuses on receptive lexical-semantic and morpho-syntactic abilities. Out of four pictures, the child has to choose one picture that best represents the sentence, which is read out to the child. 31 items were presented and one point was given for each correct response, yielding a maximum score of 31. The score was then converted into a T-score. The reliability (Cronbach's alpha) was .91 for this subtest. 
The subtest "Grammatical development" analyses the extent to which children can apply morphologic rules of German (plural, comparative, superlative, perfect tenses) by using pictures and prompting sentences which the child is asked to complete.

41 items were presented. Each correct response scored one point, yielding a maximum score of 41 . This score was then converted into a T-score. The reliability (Cronbach's alpha) was .93 for this subtest.

\section{Memory Span}

Short-term memory was assessed by the subtest "Number Recall" from the Kaufman Assessment Battery for Children (Melchers \& Preuss, 2003). The task was to repeat series of digits (2-6) in correct sequential order. The number of correct answers was converted into a T-score with a mean of 50 and a standard deviation of 10 points. The reliability for this subtest ("split-half reliability") lies between .80 and .86 for the age group of the children participating in this study.

\section{Nonverbal abilities}

As a parameter for nonverbal cognitive abilities, the "Triangles" Subtest of the Kaufman Assessment Battery for Children (Melchers \& Preuss, 2003) was used. The number of correct answers was converted into a T-score with a mean of 50 and a standard deviation of 10 points. The reliability for this subtest ("split-half reliability") is said to be between .80 and .88 for the age group of the children participating in this study.

\section{Reading and Spelling Measures}

Reading fluency was tested using the "Wuerzburger Leise Leseprobe" (WLLP-R, [Wuerzburger Silent Reading Test-revised], Schneider et al., 2011), a multiple-choice speed test. The child is asked to select one out of a choice of four pictures and match it with the corresponding word. The aim is to find as many word-picture matches as possible within five minutes. One point was given for each correct response. The final score was converted into a T-score with a mean of 50 and a standard deviation of 10 points.

The reliability ("retest reliability") is .77 for the age group of the children participating in this study.

For the tests date at the end of grade one, an additional experimental test of reading speed was designed. It consisted of two word lists and was particularly meant to assess the efficacy of the training on the sublexical level ("word recognition quick as a flash", Mayer, 2012, Chapter 5.4). The first list (training words) was made up of words that were trained in the context of the training of direct word recognition. The second list (generalization words) was composed of words that had not been part of the training but that contained one of the orthographic patterns that had been part of the training. The total number of correctly read words within two minutes (training words) or within one minute (generalization words) was the figure used for the analyses.

In order to assess reading comprehension, ELFE 1-6 (Schneider \& Lenhardt, 2006) was implemented. It comprises three subtests which test comprehension on the word, sentence and text level. On the word level, the children are asked to match a picture with one out of a set of four words. On the sentence level, the children have to complete a sentence via gap-fill, choosing one appropriate word out of five. The text level comprises short stories which are read silently by the child. Afterwards, the child is required to answer multiple choice questions about these stories.

In each part of the test, one point was given for each correct response. These scores were subsequently converted into a T-score with a mean of 50 and a standard deviation of 10 points. Moreover, the test offered a combined total score for reading comprehension.

The reliability ("split-half reliability") at the end of grade one is .89 for word comprehension, .87 for sentence comprehension and .82 for text comprehension. The respective figures for the end of grade two are $.91, .90, .91$.

Spelling abilities were tested by means of the "Deutscher Rechtschreibtest fuer die erste und zweite Klasse" (DERET 1-2+ [German Spelling Test for first and second grades], Stock \& Schneider, 2008). In this test, children were required to write a short story of 52 words from dictation. The critical value was the number of mistakes, converted into a percentile rank for the purpose of further processing the data. Because the results in the standardization sample were not normally distributed, no T-scores could be generated.

Reliability, determined by calculating the internal consistency (Cronbach's alpha) as well as the split-half coefficient is .90 at the end of grade one and .92 at the end of grade two.

\subsection{Intervention Programmes}

Training phonological awareness: The intensity and the content of the training of phonological awareness in the first half of grade one were the same in IG 1 und IG 2. It comprised two training units per week, each taking 
about 40 minutes. Thus, over a time period of 14 weeks, 28 training units were conducted. During the training, the children learned the identification and production of rhyming words, the segmentation of words into syllables, the synthesis of individual syllables into words, the identification and categorization of initial and final sounds in words as well as phoneme synthesis and phoneme segmentation. The content structure of the programme and the learning goals are illustrated in Table 1.

Table 1. Goals and contents of the training in phonological awareness

\begin{tabular}{|c|c|c|}
\hline & Rhyming (2 Weeks) & Syllables (2 Weeks) \\
\hline $\begin{array}{l}\text { Learning } \\
\text { Goals }\end{array}$ & $\begin{array}{l}\text { Recognising whether two words rhyme; finding } \\
\text { and producing rhymes. }\end{array}$ & $\begin{array}{l}\text { Segmenting words into syllables and } \\
\text { synthesising syllables to words. } \\
\text { Comparing words with regard to their length by } \\
\text { identifying the number of syllables. }\end{array}$ \\
\hline & $\begin{array}{l}\text { Identifying Initial and Final Sounds } \\
\text { (4 Weeks) }\end{array}$ & $\begin{array}{l}\text { Phoneme Synthesis and Phoneme Analysis (6 } \\
\text { Weeks) }\end{array}$ \\
\hline Learning & Identifying initial sounds & Speaking words clearly and stretching them \\
\hline Goals & $\begin{array}{l}\text { Categorizing words according to initial sounds } \\
\text { Identifying final sounds } \\
\text { Categorizing words according to final sounds }\end{array}$ & $\begin{array}{l}\text { Synthesising phonemes to words } \\
\text { Segmenting words into phonemes and using } \\
\text { character cards to spell out words } \\
\text { Segmenting words into phonemes and writing } \\
\text { them } \\
\text { Synthesising sounds to words }\end{array}$ \\
\hline
\end{tabular}

Despite the fact that nowadays trainings of phonological awareness play a role in German speaking countries, too, most of them are to a large extent conducted unsystematically in the classroom reading and writing lessons or programmes are used that need to be seen critically in terms of their quality due to insufficient linguistic foundation. The training that was designed for this study stands out from other established programmes especially when it comes to phoneme awareness. Special attention was paid to the choice of words according to linguistic criteria.

In the identification of word initial and final sounds as well as the phoneme synthesis and segmentation, only words were used that begin or end with a vowel or a consonant that can be stretched in articulation (for example [m], [f] etc.), as these are easier for children to perceive and the children can be supported in phonological processing when the relevant sounds are stretched in articulation. Furthermore, at the phoneme level only words with a simple syllable structure $(\mathrm{CV}, \mathrm{VC}, \mathrm{CVC}, \mathrm{VCV}, \mathrm{CVCV}, \mathrm{VCVC})$ were used in the beginning, in order not to overstrain the children' s phonological processing capacities.

Finally, the "phonological linkage hypothesis" (Hatcher et al., 1994) was taken into consideration early on in the training. Character cards were already used in the very first word-initial sound-identification exercises from week five of the training onwards. Phoneme synthesis and phoneme segmentation were already supported by characters within the first few lessons, so that the children were able to read and write their first words during the training, or to create words by laying down the character cards in the appropriate order.

\section{Training automatized word recognition}

In German-speaking countries, children are expected to automatize word recognition gradually by themselves once they have developed adequate phonological awareness as a basis and once they have mastered the skill of phonological recoding ("self-teaching mechanism", Share, 1995). Extensive reading experience in school and in their free time is expected to be sufficient practice. This is why systematic trainings aiming at a direct reading strategy hardly plays a role in the regular school system of German-speaking countries. 
Since dyslexic children in countries with transparent orthographies stand out particularly with regard to their deficit in reading speed, it is necessary to offer teachers at regular schools evidence-based programmes that aim at automatized word recognition. For this purpose, "Blitzschnelle Worterkennung" (Mayer 2012 [word recognition quick as a flash]) was developed for this study. The training programme was conducted with the same content and intensity in the IG 2 and IG 3 in the second half of grade one. Up to then, a comparable training programme did not exist in German-speaking countries.

10 training units are conducted over a time period of 10 weeks ( 2 units per week). Each unit takes about 45 minutes.

The training focuses on 30 orthographic patterns which frequently occur in the German orthography. Each unit focuses on three sublexical entities simultaneously (for example $<$ echt $>$, $<$ ecke $>$, $<$ auch $>$ ). First, these entities are practised in isolation before they are trained within a lexicon consisting of seven words. Each unit thus works with a total of 21 words. In the first lesson of each unit, the children practice the rapid recognition of the isolated patterns. The focused orthographic patterns are presented in different colours which are consistently used throughout the programme to have as strong a signal effect as possible.

In the second part of each unit, the children are confronted with the actual training words (for ex. $<$ schlecht $>$ [bad], $<$ Decke $>$ [blanket], $<$ tauchen $>$ [diving]). Each of these words contains one of the sublexical entities in focus as a central element. As a first step, the children have the opportunity to process the words by phonological recoding.

In the next part of the training, the children practice automatized recognition of the training words in as high a frequency as possible, in child-appropriate exercises and games. Here, the visual emphasis of the focused patterns as well as the grouping into orthographic patterns is reduced gradually.

\section{Results}

\subsection{Characteristics of Participants}

Out of all children tested in grade one $(n=1002), 8.5 \%(n=85,52.6 \%$ male, average age: $6 ; 4$, SD: $0 ; 4)$ had a double deficit. Because of the school-based randomized attribution of whole classes to the training settings, considerable differences in terms of group size between the four groups had to be accepted.

When the study started, there were 28 students in the group "phonological training only" (IG 1), 25 children in the group "phonological and word recognition training" (IG 2), 15 pupils in the group "word recognition training only" (IG 3) and 17 children received "business as usual" (CG).

The pre-intervention test battery included seven measures. The test results for the whole group and each group separately is shown in Table 2. Double-deficit children in the four groups were approximately matched on RAN, phonological awareness, nonverbal cognitive abilities, language comprehension and grammatical development. One-way ANOVAs comparing the means of the four groups for phonological awareness $(\mathrm{F}(3,84)=2.09$, $\mathrm{p}$ $=.16)$, RAN digits $(\mathrm{F}(3,84)=1.25, \mathrm{p}=.30)$, RAN colours $(\mathrm{F}(3,84)=1.33, \mathrm{p}=.27)$, language comprehension $(\mathrm{F}(3,84)=.96 \mathrm{p}=.42)$, grammatical development $(\mathrm{F}(3,82)=.75, \mathrm{p}=.53)$ and nonverbal intelligence $(\mathrm{F}(3,81)$ $=.44, \mathrm{p}=.73$ ) revealed no significant differences between the four groups.

With regard to short-term memory, the one-way ANOVA revealed significant differences between the four groups $(\mathrm{F}(3,81)=3.04, \mathrm{p}=.04)$. LSD post-hoc tests showed that children of the IG 1 and IG 3 outperformed children of the IG 2.

Despite these statistically rather limited significant differences with regard to the short-term memory, the four groups can be seen as sufficiently parallelized with regard to the predictors.

The same analyses were conducted for only those double-deficit children that had been tested at all test dates. These analyses led to comparable results. This time, the differences in short-term memory performance were not statistically significant $(\mathrm{F}(60,3)=1.64, \mathrm{p}=.19)$.

Table 2 clearly shows that the double-deficit group performed roughly two standard deviations below the mean with regard to phonological awareness and rapid automatized naming and is thus massively affected. The means for the other linguistic-cognitive variables indicate that the relevant group is also negatively affected when it comes to short term memory and nonverbal cognitive abilities. With respect to the oral language skills, the results show a clear tendency towards below-average performance. For this reason it cannot be ruled out that low performance in terms of the other documented predictors could also influence the efficacy of the training alongside a deficit in phonological awareness and in naming speed. 
Table 2. Cognitive abilities preintervention (T-scores, $M, S D$ )

\begin{tabular}{|c|c|c|c|c|c|c|}
\hline Group & & & & & & \\
\hline Tests & Total $(\mathrm{N}=85)$ & IG $1(n=28)$ & IG $2(n=25)$ & IG $3(n=15)$ & $\mathrm{CG}(\mathrm{n}=17)$ & Sign. \\
\hline Preintervention & $\mathrm{M}(\mathrm{SD})$ & $\mathrm{M}(\mathrm{SD})$ & $\mathrm{M}(\mathrm{SD})$ & $\mathrm{M}(\mathrm{SD})$ & $\mathrm{M}(\mathrm{SD})$ & \\
\hline Phonological & $32.20(4.81)$ & $30.54(4.25)$ & $32.29(3.44)$ & $33.83(4.96)$ & $33.35(4.25)$ & n.s. \\
\hline \multicolumn{7}{|l|}{ Awareness } \\
\hline RAN Digits & $33.08(7.26)$ & 33.11 (7.99) & $35.24(6.14)$ & 33.11 (7.99) & $31.56(7.70)$ & n.s. \\
\hline RAN Colours & $34.74(5.41)$ & $33.70(5.42)$ & $36.56(5.42)$ & $33.70(6.42)$ & $33.33(6.37)$ & n.s. \\
\hline Language & $44.73(9.71)$ & $45.30(9.51)$ & $42.21(9.78)$ & 46.57 (6.87) & $45.88(11.86)$ & n.s. \\
\hline \multicolumn{7}{|l|}{ Comprehension } \\
\hline Grammatical & $41.56(11.12)$ & $42.44(12.46)$ & $40.38(8.00)$ & $40.29(9.61)$ & $42.88(14.14)$ & n.s. \\
\hline \multicolumn{7}{|l|}{ Development } \\
\hline Short-Term & $43.91(9.16)$ & 46.15 (8.48) & 39.54 (7.17) & $46.15(9.02)$ & $44.82(11.20)$ & IG $1,3>$ IG 2 \\
\hline Memory & & & & & & $(\mathrm{p}=.04)$ \\
\hline Cognitive Abilities & $42.41(9.50)$ & $43.96(10.10)$ & $41.29(8.78)$ & 40.69 (7.79) & $42.82(10.97)$ & n.s. \\
\hline
\end{tabular}

\subsection{Effects of Intervention at the End of Grade 1}

The effects of the intervention are presented in Tables 3 and 4.

It was not possible to measure reading and spelling skills pre-intervention because in Germany no standardized test exists for the beginning of the first year of compulsory schooling. Consequently, we were not able to determine the effects of the intervention by comparing the achievement of the four groups pre- and post-intervention. Therefore, general effects of the interventions were analysed by means of eight one-way ANOVAs with group (four levels) as the between-subject factor, and the reading and spelling measures as the dependent variables. At the end of grade one, the ANOVAs show significant differences between the four groups for the two experimental tests of reading speed $(\mathrm{F}(3,78)=2.70, \mathrm{p}<.05$ and $\mathrm{F}(3,78)=2.60, \mathrm{p}<.05)$, the standardized test of reading fluency (WLLP-R) $(\mathrm{F}(3,78)=2.90, \mathrm{p}<.05)$ as well as sentence comprehension $(\mathrm{F}(3$, $79)=2.70, p<.05$ ). All of these differences can be traced back to statistically significant outperformance of all the IGs compared to the CG $(\mathrm{p}<.05)$. Even though there were headstart tendencies for all IGs in the other reading and writing tests, no statistically significant differences could be made out. There were no relevant differences between the three IGs.

However, to merely detect a significant supremacy of the IG compared to the CG or to detect the lack of statistically relevant differences between the groups is not sufficient to prove the practical relevance of intervention at school. If the sample is large enough, minimal differences between groups can be statistically relevant, even though they might be less relevant from a practical perspective. On the other hand, effects that are relevant in the field may not be proven to be significant if the sample is too small (Rost 2007). The size of the sample in this study was rather small due to the drop-outs described earlier (see chapter 5.1). Hence, Cohen's d effect sizes were additionally calculated. In contrast to simple variance analyses, these can provide information about the practical relevance of an identified difference between any two groups (Field, 2013).

Post-intervention scores could not be compared with pre-test scores to calculate effect sizes because reading and spelling measures from before the intervention were not available. For the same reason, the scores were thus compared between the groups.

According to Cohen (1988), $\mathrm{d}=.20-.50$ can be considered a small effect, $\mathrm{d}=.50-.80$ a moderate effect, and $\mathrm{d}$ $=.80$ or above a large effect. 
Table 4 compares the three IGs to the CG by calculating effect sizes. It becomes obvious that moderate to large effects can be demonstrated for the three IGs.

Table 3. Effects of the intervention (end of Grade 1, N=78)

\begin{tabular}{|c|c|c|c|c|c|}
\hline Reading & $\begin{array}{l}\text { IG } 1(n=28) \\
M(S D)\end{array}$ & $\begin{array}{l}\text { IG } 2(n=25) \\
M(S D)\end{array}$ & $\begin{array}{l}\text { IG } 3(n=15) \\
M(S D)\end{array}$ & $\begin{array}{l}\mathrm{CG}(\mathrm{n}=17) \\
\mathrm{M}(\mathrm{SD})\end{array}$ & $\begin{array}{l}\text { Significa } \\
\text { nce }\end{array}$ \\
\hline Spelling Measures & & & & & \\
\hline $\begin{array}{l}\text { Reading Fluency } \\
\text { (trained words) }^{\mathrm{a}}\end{array}$ & $21.00(21.52)$ & $22.80(21.05)$ & $20.67(18.64)$ & $10.53(10.22)$ & $\begin{array}{l}\text { IG } 1, \text { IG } 2> \\
\text { CG }(p<.05)\end{array}$ \\
\hline $\begin{array}{l}\text { Reading Fluency } \\
\text { (generalisation } \\
\text { words) }^{\mathrm{b}}\end{array}$ & $10.56(10.89)$ & $10.16(8.86)$ & $8.00(8.16)$ & $5.06(4.83)$ & $\begin{array}{l}\text { IG } 1, \text { IG } 2> \\
\text { CG }(p<.05)\end{array}$ \\
\hline $\begin{array}{l}\text { Reading Fluency } \\
(\text { WLLP-R) }\end{array}$ & $37.92(9.61)$ & $38.04(9.33)$ & $37.25(9.88)$ & $32.59(7.26)$ & $\begin{array}{l}\text { IG 1, IG 2, IG } \\
3 \quad>\quad \text { CG } \\
(\mathrm{p}<.05)\end{array}$ \\
\hline $\begin{array}{l}\text { Reading } \\
\text { comprehension } \\
\text { (word-level) }^{\mathrm{d}}\end{array}$ & $39.48(8.69)$ & $38.24(8.45)$ & $38.88(6.99)$ & $36.01(7.80)$ & n.s. \\
\hline $\begin{array}{l}\text { Reading } \\
\text { comprehension } \\
\text { (text-level) }^{\mathrm{f}}\end{array}$ & $41.56(6.06)$ & $41.99(7.97)$ & $41.92(4.31)$ & $39.08(4.62)$ & n.s. \\
\hline $\begin{array}{l}\text { Reading } \\
\text { comprehension } \\
\text { (Total) }\end{array}$ & $37.13(10.40)$ & $37.18(7.62)$ & $37.26(5.16)$ & $33.41(3.80)$ & n.s. \\
\hline Spelling ${ }^{\mathrm{g}}$ & $16.80(18.15)$ & $24.48(23.47)$ & $21.36(20.24)$ & $15.41(19.43)$ & n.s. \\
\hline
\end{tabular}

${ }^{a}$ Number of correctly read words within two minutes ${ }^{b}$ Number of correctly read words within one minute ${ }^{c}$ Wuerzburger Silent-Reading Test (T-score) ${ }^{\mathrm{d}}$ ELFE 1-6, Word Level (T-score) ${ }^{\mathrm{e}}$ ELFE 1-6 Sentence Level (T-score) ${ }^{\mathrm{f}}$ ELFE 1-6 Text Level (T-score) ${ }^{\mathrm{g}}$ German Spelling Test (Percentile Rank) 
Table 4. Effects of the intervention (Cohen's d) (at the end of Grade 1)

\begin{tabular}{|c|c|c|c|}
\hline & \multicolumn{2}{|c|}{ Group-Comparison } & \multirow[b]{2}{*}{ IG 3-CG } \\
\hline $\begin{array}{l}\text { Reading and Spelling } \\
\text { Measures }\end{array}$ & IG 1-CG & IG 2-CG & \\
\hline $\begin{array}{l}\text { Reading Fluency } \\
\text { (trained words) }\end{array}$ & 0.62 & 0.74 & 0.75 \\
\hline $\begin{array}{l}\text { Reading Fluency } \\
\text { (generalisation words) }\end{array}$ & 0.65 & 0.71 & 0.50 \\
\hline $\begin{array}{ll}\text { Reading } & \text { Fluency } \\
\text { (WLLP-R) } & \end{array}$ & 0.63 & 0.65 & 0.57 \\
\hline $\begin{array}{l}\text { Reading comprehension } \\
\text { (word-level) }\end{array}$ & 0.42 & 0.27 & 0.41 \\
\hline $\begin{array}{l}\text { Reading comprehension } \\
\text { (sentence-level) }\end{array}$ & 0.90 & 0.82 & 1.24 \\
\hline $\begin{array}{l}\text { Reading comprehension } \\
\text { (text-level) }\end{array}$ & 0.46 & 0.45 & 0.55 \\
\hline $\begin{array}{l}\text { Reading comprehension } \\
\text { (Total) }\end{array}$ & 0.48 & 0.63 & 0.90 \\
\hline Spelling ${ }^{\mathrm{g}}$ & 0.07 & 0.42 & 0.35 \\
\hline
\end{tabular}

\subsection{Effects of the Intervention at the End of Grade 2}

Results of the one-way ANOVAs that compared the means of the four groups at the end of grade two revealed significant main effects of the factor "group" for reading fluency $(\mathrm{F}(60,3)=2.25, \mathrm{p}<.05)$, reading comprehension (word level: $\mathrm{F}(60,3)=2.78, \mathrm{p}<.05$; text level: $\mathrm{F}(60,3)=1.85, \mathrm{p}<.05)$ and spelling $(\mathrm{F}(60,3)$ $=3.65, \mathrm{p}=.02)$. Both, IG 1 and IG 2, achieved significantly higher scores on reading fluency and reading comprehension (word level) compared to the CG $(\mathrm{p}=.05)$. In reading comprehension (sentence level), the IG 1 achieved significantly better results compared to the $\mathrm{CG}(\mathrm{p}=.05)$. In reading comprehension (text level), the IG 2 scored significantly higher than the CG $(\mathrm{p}=.05)$. A combined score for reading comprehension revealed significantly better achievements for IG 1 and IG 2 compared to the CG $(p<.05)$. Finally, for spelling, the combined training in the IG 2 led to significantly better results compared to the CG and to IG 3 (p $<.01$ ) (Table $5)$.

Table 6 shows the comparison of the three experimental groups with the control group with regard to the effect size measure. For the most part, it shows moderate to large effects in favour of the three IGs. The effects are particularly striking in reading comprehension. 
Table 5. Effects of the intervention (end of Grade 2, N=61)

\begin{tabular}{|c|c|c|c|c|c|}
\hline \multicolumn{6}{|c|}{ Group } \\
\hline & IG $1(n=24)$ & IG $2(n=20)$ & IG $3(n=9)$ & $\mathrm{CG}(\mathrm{n}=8)$ & Sign. \\
\hline & $\mathrm{M}(\mathrm{SD})$ & $\mathrm{M}(\mathrm{SD})$ & $\mathrm{M}(\mathrm{SD})$ & $\mathrm{M}(\mathrm{SD})$ & \\
\hline \multicolumn{6}{|l|}{ Reading and } \\
\hline \multicolumn{6}{|l|}{ Spelling Measures } \\
\hline $\begin{array}{l}\text { Reading Fluency } \\
\text { (WLLP-R) }\end{array}$ & $42.67(6.49)$ & $40.00(7.87)$ & $44.00(7.41)$ & $38.50(5.66)$ & $\begin{array}{l}\text { IG 1, IG } 3> \\
\text { CG }(p=.05)\end{array}$ \\
\hline $\begin{array}{l}\text { Reading } \\
\text { comprehension }\end{array}$ & $44.63(7.15)$ & $40.88(6.80)$ & $42.98(8.60)$ & $36.42(6.82)$ & $\begin{array}{l}\text { IG } 1, \text { IG } 3> \\
\text { CG }(p<.05)\end{array}$ \\
\hline \multicolumn{6}{|l|}{$(\text { word-level) })^{b}$} \\
\hline Reading & $42.51(8.77)$ & $40.88(7.04)$ & $39.11(6.78)$ & $37.45(7.91)$ & IG $1>C G(p$ \\
\hline \multicolumn{6}{|l|}{$\left(\right.$ sentence-level) ${ }^{\mathrm{c}}$} \\
\hline $\begin{array}{l}\text { Reading } \\
\text { comprehension } \\
\text { (text-level) }^{\mathrm{d}}\end{array}$ & $39.59(9.42)$ & $42.46(8.73)$ & $42.78(7.38)$ & $36.26(6.34)$ & $\begin{array}{l}\text { IG } 2>C G(p \\
=.05)\end{array}$ \\
\hline Reading & $40.28(7.61)$ & $39.81(6.86)$ & $39.84(6.43)$ & $34.31(6.55)$ & IG 1, IG $2>$ \\
\hline comprehension & & & & & $\mathrm{CG}(\mathrm{p}<.05)$ \\
\hline \multicolumn{6}{|l|}{ (Total) } \\
\hline \multirow[t]{2}{*}{ Spelling ${ }^{\mathrm{e}}$} & $33.62(27.01)$ & $44.68(27.55)$ & $19.68(8.51)$ & $17.61(14.41)$ & IG $2>$ IG 3 , \\
\hline & & & & & $\mathrm{CG}(\mathrm{p}<.01)$ \\
\hline
\end{tabular}

${ }^{a}$ Wuerzburger Silent-Reading Test (T-score) ${ }^{b}$ ELFE 1-6, Word Level (T-score) ${ }^{c}$ ELFE 1-6 Sentence Level (T-score) ${ }^{\mathrm{d}}$ ELFE Text Level (T-score) ${ }^{\mathrm{e}}$ German Spelling Test (Pecentile Rank)

Table 6. Effects of the intervention (Cohen's d) (at the end of Grade 2)

\begin{tabular}{|c|c|c|c|}
\hline & \multicolumn{2}{|c|}{ Group-Comparison } & \multirow[b]{2}{*}{ IG 3-CG } \\
\hline & IG 1-CG & IG 2-CG & \\
\hline $\begin{array}{l}\text { Reading and Spelling } \\
\text { Measures }\end{array}$ & & & \\
\hline $\begin{array}{l}\text { Reading Fluency } \\
\text { (WLLP-R) }\end{array}$ & .71 & .22 & .72 \\
\hline $\begin{array}{l}\text { Reading comprehension } \\
\text { (word-level) }\end{array}$ & 1.22 & .69 & .90 \\
\hline
\end{tabular}




\begin{tabular}{lccc}
\hline $\begin{array}{l}\text { Reading comprehension } \\
\text { (sentence-level) }\end{array}$ & .62 & .44 & .23 \\
$\begin{array}{l}\text { Reading comprehension } \\
\text { (text-level) }\end{array}$ & .40 & .81 & .78 \\
$\begin{array}{l}\text { Reading comprehension } \\
\text { (Total) }\end{array}$ & .86 & .86 & .91 \\
Spelling & .72 & 1.17 & .18 \\
\end{tabular}

A major question was whether double-deficit children in the $\mathrm{CG}$, in other words, children who did not receive any training initiated by the study at hand, actually belonged to the children showing the worst performance in terms of reading and spelling abilities. In order to answer this question, the performance of these children at the end of grade one and two was compared to the performance of no deficit and single-deficit children of the same group.

One-way ANOVAs at the end of grade one show highly significant differences between the four groups (reading fluency: $\mathrm{F}(244,3)=30.04, \mathrm{p}<.01$; reading comprehension word level: $\mathrm{F}(245,3)=20.29, \mathrm{p}<.01$; reading comprehension sentence level: $\mathrm{F}(245,3)=22.49, \mathrm{p}<.01$; reading comprehension text level: $\mathrm{F}(245,3)=11.73$, $\mathrm{p}$ $<.01$; reading comprehension total score: $\mathrm{F}(244,3)=23.94, \mathrm{p}<.01$; spelling: $\mathrm{F}(236,3)=12.60, \mathrm{p}<.01$. The same analyses at the end of grade two reveal highly significant differences between the four groups (reading fluency: $\mathrm{F}(204,3)=11.25, \mathrm{p}<.01$; reading comprehension word level: $\mathrm{F}(204,3)=9.30, \mathrm{p}<.01$; reading comprehension sentence level: $\mathrm{F}(203,3)=11.40, \mathrm{p}<.01$; reading comprehension text level: $\mathrm{F}(204,3)=12.38, \mathrm{p}$ $<.01$; reading comprehension total score: $\mathrm{F}(204,3)=11.75$, $\mathrm{p}<.01$; spelling: $\mathrm{F}(202,3)=7.70, \mathrm{p}<.01$. Post-hoc tests (LSD) showed that both children with no deficit and children with a single deficit scored significantly better on all measures than the double-deficit group. Whereas the children of the no-deficit group consistently showed average performance, children with a single deficit performed about one standard deviation below the mean, and children with a double deficit about two standard deviations below (see Table 7 for detailed results of grade 1).

Table 7. Results on the reading and spelling tests for the, "No-Deficit", "Single-Deficit" and "Double-Deficit" children of the CG (M, SD; End of Grade 1)

\begin{tabular}{|c|c|c|c|c|c|}
\hline \multicolumn{6}{|c|}{ Group } \\
\hline \multirow{4}{*}{$\begin{array}{l}\text { Reading and } \\
\text { Spelling } \\
\text { Measures }\end{array}$} & \multirow{4}{*}{$\begin{array}{l}\text { "no-deficit" } \\
(\mathrm{n}=178) \\
\mathrm{M}(\mathrm{SD})\end{array}$} & \multirow{4}{*}{$\begin{array}{l}\text { "phonologcalaw } \\
\text { areness deficit" } \\
(\mathrm{n}=25) \\
\mathrm{M}(\mathrm{SD})\end{array}$} & "naming-speed & \multirow{4}{*}{$\begin{array}{l}\text { "double deficit" } \\
(\mathrm{n}=17) \\
\mathrm{M}(\mathrm{SD})\end{array}$} & \multirow[t]{4}{*}{ Significance } \\
\hline & & & deficit” & & \\
\hline & & & $(\mathrm{n}=29)$ & & \\
\hline & & & $\mathrm{M}(\mathrm{SD})$ & & \\
\hline Reading & $53.43(31.89)$ & $23.96(18.07)$ & $25.34(17.76)$ & $10.53(10.22)$ & no-deficit> \\
\hline $\begin{array}{l}\text { Fluency } \\
\text { (trained words) }^{\mathrm{a}}\end{array}$ & & & & & $\begin{array}{l}\text { pad } \sim \text { nsd }>\text { dd }(p \\
<.001)\end{array}$ \\
\hline Reading & $23.51(15.16)$ & $11.08(8.11)$ & $12.10(8.59)$ & $5.06(4.83)$ & no-deficit \\
\hline Fluency & & & & & $\mathrm{pad} \sim \mathrm{nsd}>\mathrm{dd}(\mathrm{p}$ \\
\hline (generalisation & & & & & $<.001)$ \\
\hline words) ${ }^{b}$ & & & & & \\
\hline
\end{tabular}




\begin{tabular}{|c|c|c|c|c|c|}
\hline $\begin{array}{l}\text { Reading } \\
\text { Fluency } \\
(\mathrm{WLLP}-\mathrm{R})^{\mathrm{c}}\end{array}$ & $53.78(11.01)$ & $41.33(11.95)$ & $42.79(12.19)$ & $32.59(7.26)$ & $\begin{array}{l}\text { no-deficit }> \\
\text { pad } \sim \text { nsd }>\text { dd }(p \\
<.001)\end{array}$ \\
\hline $\begin{array}{l}\text { Reading } \\
\text { comprehension } \\
\text { (word-level) }^{\mathrm{d}}\end{array}$ & $51.31(9.90)$ & $42.79(8.80)$ & 43.09 (10.09) & $36.01(7.80)$ & $\begin{array}{l}\text { no-deficit }> \\
\text { pad } \sim \text { nsd }>\text { dd }(\mathrm{p} \\
<.001)\end{array}$ \\
\hline $\begin{array}{c}\text { Reading } \\
\text { comprehension } \\
\text { (sentence-level }^{\mathrm{e}}\end{array}$ & $51.40(11.55)$ & $40.56(7.99)$ & $42.26(8.15)$ & $34.21(2.85)$ & $\begin{array}{l}\text { no-deficit }> \\
\text { pad } \sim \text { nsd }>\text { dd }(p \\
<.001)\end{array}$ \\
\hline $\begin{array}{l}\text { Reading } \\
\text { comprehension } \\
\left(\text { text-level) }{ }^{\mathrm{f}}\right.\end{array}$ & $48.30(9.11)$ & $42.01(7.47)$ & $42.32(6.51)$ & $39.08(4.62)$ & $\begin{array}{l}\text { no-deficit }> \\
\text { pad } \sim \text { nsd }>\text { dd }(\mathrm{p} \\
<.001)\end{array}$ \\
\hline $\begin{array}{l}\text { Reading } \\
\text { comprehension } \\
\text { (Total) }\end{array}$ & 49.13 (10.37) & $37.78(10.07)$ & $40.65(8.05)$ & $33.41(3.80)$ & $\begin{array}{l}\text { no-deficit }> \\
\text { pad } \sim \text { nsd }>\text { dd }(p \\
<.001)\end{array}$ \\
\hline Spelling ${ }^{\mathrm{g}}$ & $46.91(28.71)$ & $26.62(23.31)$ & 25.68 (19.43) & $15.41(19.43)$ & $\begin{array}{l}\text { no-deficit }> \\
\text { pad } \sim \text { nsd }>\text { dd }(\mathrm{p} \\
<.001)\end{array}$ \\
\hline
\end{tabular}

\footnotetext{
${ }^{a}$ Number of correctly read words within two minutes ${ }^{b}$ Number of correctly read words within one minute ${ }^{c}$ Wuerzburger Silent-Reading Test (T-score) ${ }^{\mathrm{d}}$ ELFE 1-6, Word Level (T-score) ${ }^{\mathrm{e}}$ ELFE 1-6 Sentence Level (T-score) ${ }^{\mathrm{f}}$ ELFE 1-6 Text Level (T-score) ${ }^{\mathrm{g}}$ German Spelling Test (Percentile Rank)
}

\subsection{The Influence of the Predictors on Performance in Reading and Writing}

In order to evaluate the influence of the documented predictors on reading and writing, simple correlation analyses (Table 8) and multiple hierarchical regression analyses were conducted (Table 9-12). For these analyses, the data of all participating children (no-deficit, single-deficit, double-deficit) were taken into account.

Correlation Analyses

With regard to the correlations between the predictors that were measured at the beginning of grade one, most correlations are significant on a level of $p<.01$. Nevertheless, their impact can be rated as ranging between minor and moderate. As expected, the closest correlation was identified between the two RAN tests $(\mathrm{r}=.70, \mathrm{p}$ $<.01)$ as well as grammatical development and language comprehension $(r=.60, p<.01)$. Significant correlations of moderate extent could be established between the two focussed sub-components of phonological processing pertaining to the double-deficit hypothesis $(\mathrm{r}=.31$ and $\mathrm{r}=.33, \mathrm{p}<.01)$.

For the purpose of clarity, the presentation of the results is reduced to reading and spelling performance at the end of grade two.

The results show that, except for short-term memory, all included linguistic and cognitive predictors significantly correlate with reading and writing competence. Yet, phonological awareness and naming speed are most closely related to performance in reading and writing. Phonological awareness was significantly related to reading fluency $(\mathrm{r}=.34, \mathrm{p}<.01)$, reading comprehension $(\mathrm{r}=.26-.42, \mathrm{p}<.01)$ and spelling $(\mathrm{r}=.37, \mathrm{p}<.01)$. RAN was significantly related to reading fluency $(r=.39, \mathrm{p}<.01)$, reading comprehension $(\mathrm{r}=.38-.43, \mathrm{p}<.01)$ and spelling $(\mathrm{r}=.35, \mathrm{p}<.01)$. Researchers commonly agree that the influence of rapid naming becomes particularly obvious when word recognition is automatized. The results of this study, however, suggest that RAN abilities are just as closely related to performance in reading and writing tests as phonological awareness, already 
at such an early stage of reading acquisition. Furthermore, no substantial differences can be found with regard to the strength in correlation of both functions and reading speed, reading comprehension and orthographic skills.

Listening comprehension and grammatical development most strongly correlate with performance on reading comprehension tests. All reported correlations were statistically consistently significant but the size of the correlation was only moderate.

Table 8. Correlation (Pearson's) between predictors and reading and spelling measures (End of Grade 2)

\begin{tabular}{|c|c|c|c|c|c|c|c|}
\hline & $\mathrm{pa}^{\mathrm{f}}$ & $\begin{array}{l}\text { RAN } \\
\text { Digits }\end{array}$ & $\begin{array}{l}\text { RAN } \\
\text { Colours }\end{array}$ & $\begin{array}{l}\text { Lang. } \\
\text { Comp }\end{array}$ & $\begin{array}{l}\text { Gramm. } \\
\text { Develop. }\end{array}$ & $\mathrm{STM}^{\mathrm{g}}$ & $\begin{array}{l}\text { Nonverbal } \\
\text { Abilities }\end{array}$ \\
\hline $\begin{array}{l}\text { Reading } \\
\text { Fluency } \\
\text { (WLLP-R) }^{\mathrm{a}}\end{array}$ & $.34 * *$ & $.39 * *$ & $.34 * *$ & $.36 * *$ & $.28 * *$ & $.17 * *$ & $.25 * *$ \\
\hline $\begin{array}{l}\text { Reading } \\
\text { comprehension } \\
\text { (word-level) }^{\mathrm{b}}\end{array}$ & $26^{* *}$ & $.39 * *$ & $.32 * *$ & $.19 * *$ & $.17 * *$ & .05 & $17 * *$ \\
\hline $\begin{array}{l}\text { Reading } \\
\text { comprehension } \\
\text { (sentence-level) }^{\mathrm{c}}\end{array}$ & $.37 * *$ & $.43 * *$ & $.37 * *$ & $.34 * *$ & $.30^{* *}$ & $.13^{*}$ & $.29 * *$ \\
\hline $\begin{array}{l}\text { Reading } \\
\text { comprehension } \\
\text { (text-level) }^{\mathrm{d}}\end{array}$ & $.42^{* * *}$ & $.38 * *$ & $.33 * *$ & $.28 * *$ & $32 * *$ & .10 & $.27 * *$ \\
\hline $\begin{array}{l}\text { Reading } \\
\text { comprehension } \\
\text { (total) }\end{array}$ & $39 * *$ & $.43 * *$ & $.36^{* *}$ & $.34 * *$ & $.31 * *$ & .11 & $.26^{* *}$ \\
\hline Spelling ${ }^{\mathrm{e}}-$ & $.37^{* * *}$ & $-.35^{*}$ & $-.28^{*}$ & $-.22 *$ & $-.24 * *$ & $-.15^{*}$ & $-.15^{*}$ \\
\hline
\end{tabular}

\section{Regression Analyses}

To improve the ability to predict the reading and spelling abilities at the end of grade one and two, several possible predictor variables (measured at the beginning of grade one: phonological awareness, RAN, language comprehension, grammatical development, short-term memory and nonverbal IQ) were retained into a regression model and stepwise regressions were conducted.

As depicted in Table 9, approximately $31 \%$ of the variance in reading fluency were explained by the combined variables of RAN, general language abilities, phonological awareness and IQ. The other predictors did not contribute significantly.

Table 10 shows that $24 \%$ of the variance in reading comprehension could be explained by the combined variables of grammatical development, RAN digits, language comprehension and IQ. The other predictors were not significant contributors.

The results of the stepwise regression analyses for spelling can be seen in Table 11. Taking together the variables of RAN, grammatical development and phonological awareness explained $14 \%$ of the variance for spelling. The other predictors were not significant contributors. 
Table 9. Results from stepwise regression analyses of reading fluency (WLLP-R)

\begin{tabular}{|c|c|c|c|c|}
\hline & $\mathrm{R}^{2}$ & $\mathrm{R}^{2}$ & $\mathrm{~F}$ & Significance \\
\hline 1. RAN-Digits & .14 & .14 & 31.84 & .0001 \\
\hline Language & .25 & .11 & 32.74 & .0001 \\
\hline \multicolumn{5}{|l|}{ comprehension } \\
\hline 3. Phonological & .29 & .04 & 27.35 & .0001 \\
\hline \multicolumn{5}{|l|}{ Awareness } \\
\hline 4. Nonverbal IQ & .31 & .02 & 22.35 & .0001 \\
\hline
\end{tabular}

Table 10. Results from stepwise regression analyses of reading comprehension (ELFE 1-6 total)

\begin{tabular}{lcccc}
\hline & $\mathrm{R}^{2}$ & $\mathrm{R}^{2}$ & $\mathrm{~F}$ & Significance \\
\hline 1. Grammatical & .11 & .11 & 25.79 & .0001 \\
Development & & & & \\
2. RAN-Digits & .19 & .08 & 24.46 & .0001 \\
3. Language & .22 & .03 & 19.90 & .0001 \\
Comprehension & & & & \\
4. Nonverbal & .24 & .02 & 16.79 & .001 \\
IQ & & & & \\
\hline
\end{tabular}

Table 11. Results from stepwise regression analyses of spelling (DERET 1-2+)

\begin{tabular}{lcccr}
\hline & $\mathrm{R}^{2}$ & $\mathrm{R}^{2}$ & $\mathrm{~F}$ & Significance \\
\hline 1. RAN-Digits & .11 & .11 & 20.14 & .0001 \\
2. Grammatical & .17 & .06 & 15.96 & .0001 \\
Development & & & & \\
3.Phonological & .20 & .03 & 12.13 & .0001 \\
Awareness & & & & \\
\hline
\end{tabular}

Additional regression analyses were conducted in order to determine the joined and the independent contributions of phonological awareness and RAN. In these analyses, only the two relevant variables were considered. Table 12 shows that the variable that was considered in step 2 could contribute significantly to all reading and writing tests and can thus additionally explain between 6 and $10 \%$ of the variance. 
Table 12. Contributions of RAN and phonological awareness to reading and spelling performance (at the end of Grade 2)

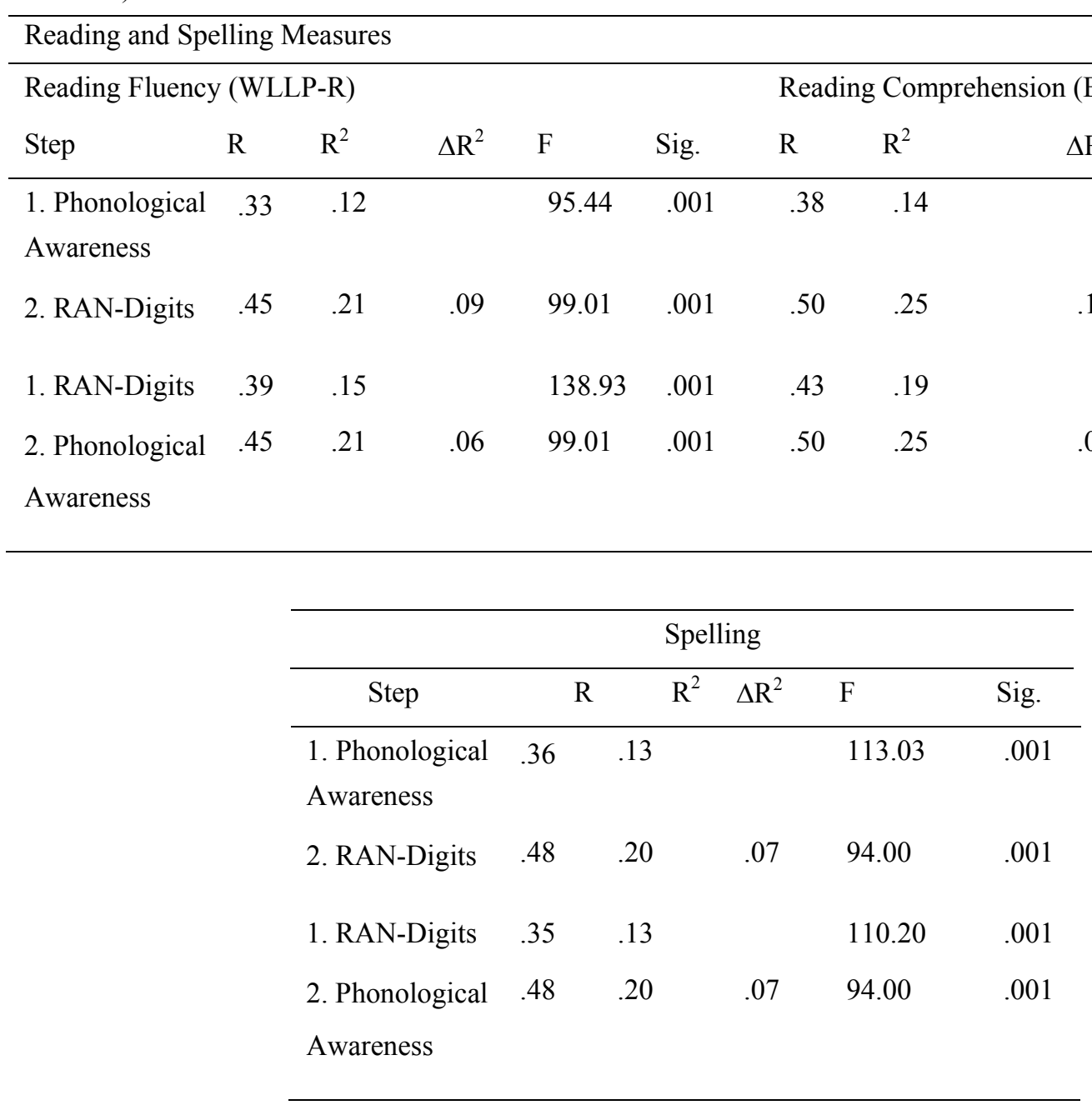

\section{Discussion}

The results of this study show that, of all included linguistic and cognitive predictors, phonological awareness and naming speed are most closely related to performance in reading and writing. At the same time, phonological awareness and rapid automatized naming only correlate moderately. Furthermore, the regression analyses suggest that the two functions above all provide largely independent contributions in accounting for variance. The results correspond to Wolf et al. (2002), who found similar correlations in a group of 144 dyslexic children in grade two (RAN letters-phoneme synthesis: $\mathrm{r}=.25, \mathrm{p}<.01$; RAN letters-phoneme elision: $\mathrm{r}=.28, \mathrm{p}$ $<.01)$. Similar results can be found in Blachmann (1984) and Cornwall (1992).

Therefore, these two factors should be given ample attention when considering the early identification of children at risk of developing dyslexia. Furthermore these results suggest that phonological skills play a role in the complex construct of rapid naming. Nevertheless, RAN should not be reduced to just this one component. Considering its implications for education, the finding that both functions have specific independent impact on the acquisition of reading and writing seems to be more relevant than the question whether both variables may be subsumed under the term of phonological processing (Wolf \& Bowers, 1999).

Even given the fact that a deficit in the rate of access to and retrieval of stored phonological information is generally taken to be the one component within the complex construct of RAN which is primarily responsible for the RAN deficit, both the rate in which phonological information is accessed and the conscious handling of phonological information (i.e., phonological awareness) obviously affect reading and writing, independently. 
It is worth mentioning that the influence of phonological awareness on reading comprehension is statistically no longer significant once the cognitive abilities have been taken into account. The correlation between IQ and phonological awareness was $r=.32,(p<.01)$ in the study at hand. The correlations between phonological awareness and reading comprehension $(\mathrm{r}=.26-.42, \mathrm{p}<.01)$ could partially be explained by the cognitive component within the construct of phonological awareness. This assumption should not apply to RAN since no correlation with IQ could be found here.

The distinct impact of naming speed on the performance in reading and writing at such an early stage in the developmental process was a rather unexpected result of the study at hand. A much stronger correlation with phonological awareness had been expected, as reading skills at this point in time are rather interpreted as mastering phonological recoding skills. Rapid naming, however, is primarily expected to come into effect once the reading process is automatized (Cornwall, 1992; Kirby et al., 2003; Wolf \& Bowers, 1999). The results of the stepwise regression analyses even suggest that the impact of RAN is tendentiously stronger than the influence of phonological awareness in terms of word recognition as well as reading comprehension and spelling.

The strong impact of RAN as early as grade one and two leads to the assumption that the speed with which visual symbols are processed and with which phonological information is retrieved not only plays an important role in the automatized processing of sublexical and lexical representations and hence in direct word recognition (Bowers et al., 1994), but also in learning the alphabetic principle of written language. The results of this study suggest that the fast access to phonological representations also influences the acquisition of the alphabetic principle of reading. RAN tests offer information on how quickly a symbol (letter) can be processed and identified and how fast a person can activate the relevant phonological information. Consequently, phonological recoding may be negatively affected by a large time lag in processing individual letters. This goes hand in hand with an overstraining of the working memory.

In the early diagnosis of dyslexia, phonological awareness as well as naming speed should be tested, as children with a double deficit develop severe difficulties when learning how to read and write unless they receive specific intervention. This assumption is supported by the results of this study, since the double-deficit children in the control group performed about one to two standard deviations below the performance of the children in the no-deficit and the single-deficit groups. This result mostly agrees with the investigations of Kirby et al. (2003), Cronin (2013) and Torppa et al. (2013).

On the other hand, this study also suggests that these children can be supported effectively in their development by methods that train phonological awareness and automatized word recognition. Indeed, the training programmes that were implemented in this study were certainly a step into the right direction. However, since not all children were able to sufficiently profit from the training, further modifications and enhancements are necessary.

The methods can be expected to prove even more effective if the intervention is not integrated into the classroom routine, but is rather conducted in small groups of children who are at risk of developing dyslexia. A more individual and intense support would be guaranteed if the intervention did not include the whole class. Having SLPs or special needs teachers, who offer supportive trainings in small and more homogeneous groups, is also a prerequisite in inclusive settings. Only then can all students get the best and most suitable individual support. Indeed, this proposal goes hand in hand with the Convention on Human Rights of Persons with Disabilities (United Nations, 2006), which explicitly states: "Specific measures which are necessary to accelerate or achieve de facto equality of persons with disabilities shall not be considered discrimination under the terms of the present Convention" (article 5, paragraph 4).

Ideally, support measures should additionally be modified so that the training of automatized word recognition on the sublexical level would only be implemented once the children have mastered phonological recoding. Most children with a double deficit in our study had probably not yet mastered this prerequisite midway in grade one. Therefore, starting this training in grade two would be more appropriate.

For the double deficit group in the study at hand, deficits in general language comprehension and expressive abilities became obvious. The regression analyses support the assumption that these difficulties could have negatively influenced reading comprehension on the sentence and text level. Hence, a comprehensive training in the context of reading and writing lessons should also include therapeutic support for expressive and receptive language skills in general.

The double-deficit group in this study showed a tendency to perform below average with regard to phonological memory, although this memory was only examined superficially. Since the working memory is a stable and 
largely invariant personality trait which, although it develops with maturity, is largely resistant to systematic training (Holmes et al. 2009), measures that acknowledge restrictions in the working memory should be integrated into school lessons. Boudreau/Constanza-Smith (2011) offer numerous suggestions how this could be done.

\section{Acknowledgments}

We gratefully acknowledge the assistance of the participating schools, teachers, students and children.

\section{Declaration of Conflicting Interests}

The author(s) declared no conflicts of interest with respect to the authorship and/or publication of this article.

\section{Funding}

The author(s) disclosed receipt of the following support for the research and/or authorship of this article:

This research was supported by the education authorities of the district Mettmann/ North Rhine-Westphalia, the special pedagogical competence centres of Velbert, Erkrath and Mettmann and the Centres for Teacher Training in Solingen and Juelich.

\section{References}

Angermeier, M. J. (2007). ETS 4-8-Entwicklungstest Sprache fuer Kinder von vier bis acht Jahren [Test of language development for children beetween 4 and 8 years]. Frankfurt: Harcourt Test Services.

Aro, M., \& Wimmer, H. (2003). Learning to read: English in comparison to six more regular orthographies. Applied Psycholinguistics, 24, 621-635. http://dx.doi.org/10.1017/S0142716403000316

Berendes, K., Schnitzler, C., Willmes, K., \& Huber, W. (2010). Die Bedeutung von Phonembewusstheit und semantisch-lexikalischen Faehigkeiten fuer Schriftsprachleistungen in der Grundschule [Importance of phoneme awareness and lexical abilities for reading and writing in elementary school]. Sprache, Stimme und Gehoer, 34, 33-41. http://dx.doi.org/10.1055/s-0029-1246203

Berglez, A. (2003). Praevention von Lese-Rechtschreibschwierigkeiten. Ein Training der Benennungsgeschwindigkeit [Prevention of dyslexia. A RAN training-study]. Dissertation, Universitaet Bielefeld.

Blachman, B. A. (1984). Relationship between rapid naming ability and language analysis. Skills to kindergarten and first-grade reading achievement. Journal of Educational Psychology, 76, 610-622. http://dx.doi.org/10.1037/0022-0663.76.4.610

Boudreau, D., \& Constanza-Smith, A. (2011). Assessment and Treatment of Working Memory Deficits in Scholl-Age Children: The Role of the Speech-Language Pathologist. Language, Speech, and Hearing Services in Schools, 42, 152-166. http://dx.doi.org/10.1044/0161-1461(2010/09-0088)

Bowers, P. G., \& Swanson, L. B. (1991). Naming speed deficits in reading disability: Multiple measures of a singular process. Journal of Experimental Child Psychology, 51, 195-219. http://dx.doi.org/10.1016/0022-0965(91)90032-N

Bowers, P. G., Golden, J. O., Kennedy, A., \& Young, A. (1994). Limits upon orthographic knowledge due to processes indexed by naming speed. In V. W. Berninger (Ed.), The varieties of orthographic knowledge: Theoretical and developmental issue (pp. 173-218). Dordrecht, Boston, London: Kluwer Academic Publishers. http://dx.doi.org/10.1007/978-94-017-3492-9_6

Bradley, L., \& Bryant, P. E. (1983). Categorizing sounds and learning to read: A causal connection. Nature, 30, 419-421. http://dx.doi.org/10.1038/301419a0

Brizzolara, W., Chilosi, A., Cipriani, A., Gasperini, F., Mazzotti, S., Pecini, C., \& Zoccolotti, P. (2006). Do phonologic and rapid automatized naming deficits differentially affect dyslexic children with and without a history of language delay? A study of Italian dyslexic children. Cognitive and Behavioral Neurology, 19, 141-149. http://dx.doi.org/10.1097/01.wnn.0000213902.59827.19

Catts, H. W., Fey, M. E., Tomblin, J. B., \& Zhang, X. (2002). A Longitudinal Investigation of Reading Outcomes in Children with Language Impairments. Journal of Speech, Language and Hearing Research, 45, 1142-1157. http://dx.doi.org/10.1044/1092-4388(2002/093)

Chenot, J. F. (2009). Cluster-randomisierte Studien: Eine wichtige Methode in der allgemeinmedizinischen Forschung [Cluster randomized studies. An important method in medical research]. Zeitschrift fuer Evidenz, 
Fortbildung und Qualitaet im Gesundheitswesen (ZEFQ), 103, 475-480. http://dx.doi.org/10.1016/j.zefq.2009.07.004

Cohen, J. (1988). Statistical power analysis for the behavioral sciences. Hillsdale: Erlbaum.

Conrad, N. J., \& Levy, B. A. (2011). Training letter and orthographic pattern recognition in children with slow naming speed. Reading and Writing: An Interdisciplinary Journal, 24, 91-115. http://dx.doi.org/10.1007/s11145-009-9202-x

Cornwall, A. (1992). The relationship of phonological awareness, rapid naming and verbal memory to severe reading and spelling disability. Journal of Learning Disabilities, 25, 532-538. http://dx.doi.org/10.1177/002221949202500808

Cronin, V. S. (2013). RAN and double-deficit theory. Journal of Learning Disabilities, 46, 182-190. http://dx.doi.org/10.1177/0022219411413544

De Jong, P. F., \& Vrielink, L. O. (2004). Rapid automatic naming: Easy to measure, hard to improve (Quickly). Annals of Dyslexia, 54, 65-88. http://dx.doi.org/10.1007/s11881-004-0004-1

Denckla, M. B., \& Rudel, R. G. (1976). Rapid automatized naming (R.A.N.). Dyslexia differentiated from other learning disabilities. Neuropsychologia, 14, 471-479. http://dx.doi.org/10.1016/0028-3932(76)90075-0

Escribano, C. L. (2007). Evaluation of the double-deficit hypothesis Subtype classification of readers in Spanish. Journal of Learning Disabilities, 40, 319-330. http://dx.doi.org/10.1177/00222194070400040301

Field, A. (2013). Discovering Statistics using IBM SPSS Statitistics (3rd ed.). Los Angeles, London: Sage Publications.

Georgiou, K. G., Parilla, R., \& Liao, C. (2008). Rapid naming speed and reading across languages that vary in orthographic consistency. Reading and Writing: An Interdisciplinary Journal, 21, 885-903. http://dx.doi.org/10.1007/s11145-007-9096-4

Hatcher, P., Hulme, C., \& Ellis, A. (1994). Ameliorating early reading failure by integrating the teaching of reading and phonological skills. Child Development, 65, 41-57. http://dx.doi.org/10.2307/1131364

Hatz, H., \& Sachse, S. (2010). Praevention von Lese-Rechtschreibstoerungen. Auswirkungen eines Trainings phonologischer Bewusstheit und eines Rechtschreibtrainings im ersten Schuljahr auf den Schriftspracherwerb bei Risikokindern [Prevention of dyslexia. Evaluation of a phonological awareness and spelling training in children at risk]. Zeitschrift fuer Entwicklungspsychologie und Paedagogische Psychologie, 42, 226-240. http://dx.doi.org/10.1026/0049-8637/a000021

Hinitikaa, S., Landerl, K., Aro, M., \& Lyythinen, H. (2008). Training reading fluency: Is it important to practice reading aloud and is generalisation possible? Annals of Dyslexia, 58, 59-79. http://dx.doi.org/10.1007/s11881-008-0012-7

Holmes, J., Gathercole, S., \& Dunning, D. L. (2009). Adaptive training leads to sustained enhancement of poor working memory in children. Developmental Science, 12, 9-15. http://dx.doi.org/10.1111/j.1467-7687.2009.00848.x

Holopainen, L., Ahonen, T., \& Lyytinen, H. (2001). Predicting delay in reading achievement in a highly transparent language. Journal of Learning Disabilities, 34, 401-413. http://dx.doi.org/10.1177/002221940103400502

Kerry, S. M., \& Bland, J. M. (1998). Statistics notes: Sample size in cluster randomisation. BMJ, 316(7130), 549. http://dx.doi.org/10.1136/bmj.316.7130.549

Kirby, J. R., Pfeiffer, S., \& Parilla, R. (2003). Naming speed and phonological awareness as predictors of reading development. Journal of Educational Psychology, 95, 453-464. http://dx.doi.org/10.1037/0022-0663.95.3.453

Kirby, J. R., Georgiou, G. K., Martinussen, R., \& Parilla, R. (2010). Naming speed and reading. From prediction to instruction. Reading Research Quarterly, 45, 341-362. http://dx.doi.org/10.1598/RRQ.45.3.4

Klicpera, C., Schabmann, A., \& Gasteiger-Klicpera, B. (2013). Legasthenie [Dyslexia]. Muenchen Basel: Reinhardt Verlag.

Landerl, K., Linortner, R., \& Wimmer, H. (1992). Phonologische Bewusstheit und Schriftspracherwerb im Deutschen [Phonological awareness and reading and writing in German]. Zeitschrift fuer Paedagogische Psychologie, 6, 17-35. 
Lenhard, W., \& Schneider, W. (2006). ELFE 1-6. Ein Leseverstaendnistest fuer Erst- bis Sechstklaessler [ELFE 1-6. A reading comprehension test for first to sixth grader]. Goettingen: Hogrefe.

Levy, B. A. (2001). Moving the bottom: Improving reading fluency. In M. Wolf (Ed.), Dyslexia, fluency, and the brain (pp. 357-378). Timonium, MD: York Press.

Levy, B. A., Bourassa, D. C., \& Horn, C. (1999). Fast and slow namers: Benefits of segmentation and whole word training. Journal of Experimental Child Psychology, 73, 115-138. http://dx.doi.org/10.1006/jecp.1999.2497

Lovett, M. W., Steinbach, K. A., \& Fritjers, J. C. (2000). Remediating the core deficits of developmental reading disability: A double deficit perspective. Journal of Learning Disablilities, 33, 334-358. http://dx.doi.org/10.1177/002221940003300406

Lundberg, I., Frost, J., \& Petersen, O. (1988). Effects of an extensive training program for stimulating phonological awareness in preschool children. Reading Research Quarterly, 23, 263-284. http://dx.doi.org/10.1598/RRQ.23.3.1

Lyon, G. R., Shaywitz, S. E., \& Shaywitz, B. A. (2003). Defining dyslexia, Comorbidity, teachers' knowledge of language and reading. A definition of dyslexia. Annals of Dyslexia, 53, 1-14. http://dx.doi.org/10.1007/s11881-003-0001-9

Manis, F. R., Doi, L. M., \& Bhadha, B. (2000). Naming speed, phonological awareness and orthographic knowledge in second graders. Journal of Learning Disabilities, 33, 325-333. http://dx.doi.org/10.1177/002221940003300405

Mayer, A. (2008). Phonologische Bewusstheit, Benenennungsgeschwindigkeit und automatisierte Leseprozesse [Phonological awareness, naming-speed and automatized word recognition]. Aachen: Shaker Verlag.

Mayer, A. (2012). BLIWO. Blitzschnelle Worterkennung [word recognition in a flash]. Dortmund: Borgmann Media.

Mayer, A. (2013). TEPHOBE. Test zur Erfassung der phonologischen Bewusstheit und der Benennungsgeschwindigkeit [Test of phonological awareness and RAN]. Muenchen: Reinhardt Verlag.

Mayer, A. (2014). Frueherkennung und Praevention von Schriftspracherwerbsstoerungen im inklusiven Unterricht [Early identification and prevention of dyslexia in an inclusive setting] (Unpublished Habilitation-Thesis). University Cologne.

Melchers, P., \& Preuss, U. (2003). Kaufmann Assessment Battery for Children: German Version. Frankfurt: Swets \& Zeitlinger.

Meyer, M. S., Wood, F., Hart, L., \& Felton, R. (1998). Selective predictive value of rapid automatized naming in poor readers. Journal of Learning Disabilities, 31, 106-117. http://dx.doi.org/10.1177/002221949803100201

Moll, K., Fussenegger, E., Willburger, E., \& Landerl, K. (2009). RAN is not a measure of orthographic processing. Evidence from the asymmetric German orthography. Scientific Studies of Reading, 13, 1-25. http://dx.doi.org/10.1080/10888430802631684

Norton, E. S., \& Wolf, M. (2012). Rapid automatized naming (RAN) and reading fluency: Implications for understanding and treatment of reading disabilities. Annual Review of Psychology, 6, 427-452. http://dx.doi.org/10.1146/annurev-psych-120710-100431

Papadopoulos, T. C., Georgiou, G. K., \& Kendeou, P. (2009). Investigating the double-deficit hypothesis in Greek. Findings from a longitudinal study. Journal of Learning Disabilities, 42, 528-547. http://dx.doi.org/10.1177/0022219409338745

Rost, D. (2007). Interpretation und Bewertung paedagogisch-psychologischer Studien. Eine Einfuehrung [Interpretation and appraisal of pedagogical-psychological studies. An introduction]. Weinheim/Basel: Beltz Verlag.

Roth, E. (1999). Praevention von Lese-und Rechtschreibschwierigkeiten. Evaluation einer vorschulischen Foerderung der phonologischen Bewusstheit und der Buchstabenkenntnis [Evaluation of phonological awareness and letter naming training in preschool children]. Frankfurt: Lang.

Schatschneider, C., \& Torgesen, J. K. (2004). Using our current understanding of dyslexia to support early identification und intervention. Journal of Child Neurology, 19, 759-765. 
Schneider, W., Blanke, I., Faust, V., \& Kuespert, P. (2011). WLLP-R. Wuerzburger Leise Leseprobe-Revision. Ein Gruppentest fuer die Grundschule [Wuerzburger silent reading test-revised]. Goettingen: Hogrefe Verlag fuer Psychologie.

Schneider, W., Kuespert, P., Roth, E., \& Marx, H. (1997). Short and long term effects of training phonological awareness in kindergarten: Evidence from two German studies. Journal of Experimental Child Psychology, 66, 311-340. http://dx.doi.org/10.1006/jecp.1997.2384

Share, D. J. (1999). Phonological recoding and orthographic learning: A direct test of the self teaching

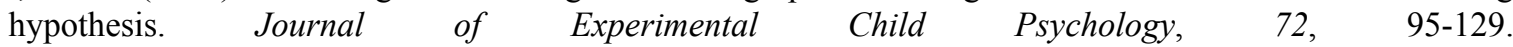
http://dx.doi.org/10.1006/jecp.1998.2481

Shaywitz, S. E., Shaywitz, B. A., Fletcher, J. M., \& Escobar, M. D. (1990). Prevalence of reading disability in boys and girls. The Journal of the American Medical Association, 264, 998-1002. http://dx.doi.org/10.1001/jama.1990.03450080084036

Stanovic, K. E. (1988). Explaining the differences between the dyslexic and garden variety poor readers: The phonological core variable difference model. Journal of Learning Disabilities, 21, 590-612. http://dx.doi.org/10.1177/002221948802101003

Stock, C., \& Schneider, W. (2008). DERET 1-2+. Deutscher Rechtschreibtest fuer das erste und zweite Schuljahr [German spelling test for first and second grader]. Goettingen: Hogrefe.

Swanson, H. L., Trainin, G., Necoechea, D. M., \& Hammill, D. D. (2003). Rapid naming, phonological awareness, and reading: A meta-analysis of the correlation evidence. Review of Educational Research, 73, 407-440. http://dx.doi.org/10.3102/00346543073004407

Swanson, H. L., Zheng, X., \& Jerman, O. (2009). Working memory, short-term memory, and reading disabilities. A selective meta-analysis of the literature. Journal of Learning Disabilities, 42, 260-289. http://dx.doi.org/10.1177/0022219409331958

Thaler, V., Ebner, E., Wimmer, H., \& Landerl, K. (2004). Training reading fluency in dysfluent readers with high reading accuracy: Word specific effects but low transfer to untrained words. Annals of Dyslexia, 54, 89-112. http://dx.doi.org/10.1007/s11881-004-0005-0

Torgesen, J. K., Wagner, R. K., \& Rashotte, C. A. (1997). Prevention and remediation of severe reading disabilities: Keeping the end in mind. Scientific Studies of Reading, 1, 217-234. http://dx.doi.org/10.1207/s1532799xssr0103_3

Torppa, M., Parrila, R., Niemi, P., Lerkkanen, M., Poikkeus, A., \& Nurmi, J. (2013). The double deficit hypothesis in the transparent Finnish orthography: A longitudinal study from kindergarten to Grade 2. Reading and Writing: An Interdisciplinary Journal, 26, 1353-1380. http://dx.doi.org/10.1007/s11145-012-9423-2

Tunmer, W. E., \& Greaney, K. (2010). Defining dyslexia. Journal of Learning Disabilities, 43, 229-243. $\mathrm{http}: / / \mathrm{dx}$.doi.org/10.1177/0022219409345009

United Nations. (2006). Convention on the Rights of Persons with Disabilities.

van Den Bos, K. P., Zijlstra, B. J. H., \& Spelberg, H. C. (2002). Life-span data on continuous naming speeds of numbers, letters, colours, and pictured objects, and word reading speed. Scientific Studies of Reading, 6, 25-49. http://dx.doi.org/10.1207/S1532799XSSR0601_02

Verhagen, W., Aarnoutse, C., \& van Leeuwe, J. (2008). Phonological awareness and naming speed in the prediction of Dutch children' s word recognition. Scientific Studies of Reading, 12, 301-324. http://dx.doi.org/10.1080/10888430802132030

Wagner, R. K., \& Torgesen, J. K. (1987). The nature of phonological processing and its causal role in the acquisition of reading skills. Psychological Bulletin, 101, 192-212. http://dx.doi.org/10.1037/0033-2909.101.2.192

Wagner, R. K., Torgesen, J. K., Laughon, P., Simmons, K., \& Rashotte, C.A. (1993). Development of young readers' phonological processing abilities. Journal of Educational Psychology, 85, 83-103. http://dx.doi.org/10.1037/0022-0663.85.1.83

Wiig, E., Secord, W., \& Semel, E. (2003). Clinical evaluation of language fundamentals preschool (CELF-P). Sidcup: Psychological Corporation. 
Wimmer, H. (1993). Characteristics of developmental dyslexia in a regular writing system. Applied Psycholinguistics, 14, 1-33. http://dx.doi.org/10.1017/S0142716400010122

Wimmer, H., \& Mayringer, H. (2002). Dysfluent reading in the absence of spelling difficulties: A specific disability in regular orthographies. Journal of Educational Psychology, 94, 272-277. http://dx.doi.org/10.1037/0022-0663.94.2.272

Wimmer, H., Landerl, K., Linortner, R., \& Hummer, P. (1991). The relationship of phonemic awareness to reading acquisition: More consequence than precondition, but still important. Cognition, 40, 219-249. http://dx.doi.org/10.1016/0010-0277(91)90026-Z

Wolf, M., \& Bowers, P. G. (1999). The double deficit hypothesis for the developmental dyslexia. Journal of Educational Psychology, 91, 415-438. http://dx.doi.org/10.1037/0022-0663.91.3.415

Wolf, M., Bally, H., \& Morris, R. (1986). Automaticity, retrieval processes and reading. A longitudinal study in average and impaired readers. Child Development, 57, 988-1000. http://dx.doi.org/10.2307/1130373

Wolf, M., Goldberg O’ Rourke, A., Gidney, C., Lovett, M. W., Cirino, P., \& Morris, R. (2002). The second deficit. An investigation of the independence of phonological and naming-speed deficits in developmental dyslexia. Reading and Writing. An Interdisciplinary Journal, 15, 43-72.

\section{Copyrights}

Copyright for this article is retained by the author(s), with first publication rights granted to the journal.

This is an open-access article distributed under the terms and conditions of the Creative Commons Attribution license (http://creativecommons.org/licenses/by/3.0/). 